\title{
In vitro and in vivo evaluation of anisomycin against Ehrlich ascites carcinoma
}

\author{
PENGTAO YOU ${ }^{*}$, FEIYUE XING ${ }^{1,2}$, JIE HUO $^{1 *}$, BAOYU WANG $^{1}$, JINGFANG DI $^{1}$, SHAN ZENG $^{1}$ and JING LIU ${ }^{3}$ \\ ${ }^{1}$ Department of Immunobiology, Institute of Tissue Transplantation and Immunology, Jinan University, \\ ${ }^{2}$ Key Laboratory of Functional Protein Research of Guangdong Higher Education Institutes, Jinan University, \\ ${ }^{3}$ Department of Stomatology, Jinan University, Guangzhou 510632, P.R. China
}

Received January 3, 2013; Accepted February 8, 2013

DOI: $10.3892 /$ or.2013.2355

\begin{abstract}
Anisomycin eminently inhibits cell proliferation in vitro. The aim of this study was to explore the potential of anisomycin to treat tumors in vivo and its mechanism(s) of action. The results showed that peritumoral administration of anisomycin significantly suppressed Ehrlich ascites carcinoma (EAC) growth resulting in the survival of approximately $60 \%$ of the mice 90 days after EAC inoculation. Enhancement of infiltrating lymphocytes was noted in the tumor tissue, which was dramatically superior to adriamycin. The growth inhibitory rate of EAC cells was enhanced with increasing concentrations of anisomycin, following an enhanced apoptotic rate. The total apoptotic rate induced by $160 \mathrm{ng} / \mathrm{ml}$ of anisomycin was higher when compared to that induced by $500 \mathrm{ng} / \mathrm{ml}$ of adriamycin. DNA breakage and nanostructure changes were also noted in the EAC cells. The levels of caspase- 3 mRNA, caspase- 3 and cleaved-caspase- 3 proteins in the anisomycin-treated EAC cells were augmented in a dose- and time-dependent manner, following the activation of caspase- 8 and caspase- 9 , which finally triggered PARP cleavage. The cleaved-caspase-3, cleaved-caspase- 8 and cleaved-caspase- 9 proteins were mainly localized in the nuclei of the cells. These results indicate that anisomycin efficaciously represses in vitro and in vivo growth of EAC cells through caspase signaling, significantly superior to the effects of adriamycin. This suggests the potential of anisomycin for the treatment of breast cancer.
\end{abstract}

Correspondence to: Dr Feiyue Xing or Dr Jing Liu, Department of Immunobiology, Institute of Tissue Transplantation and Immunology, Jinan University, Guangzhou 510632, P.R. China

E-mail: tfyxing@jnu.edu.cn

E-mail: tjliu@jnu.edu.cn

${ }^{*}$ Contributed equally

Key words: anisomycin, apoptosis, caspases, therapy, Ehrlich ascites carcinoma

\section{Introduction}

Cancer chemotherapy is a rapidly growing field of oncology. Significant progress can be achieved in the prevention and treatment of carcinogenesis by administration of various drugs with chemical or natural entities depending on their anti-mutagenic properties (1). Progress in the understanding of the detailed pharmacological and chemical properties of various agents may improve and establish an appropriate strategy for the therapy of cancer (2). Anisomycin [2-(p-methoxybenzyl)-3,4-pyrrolidinediol-3-acetate] was first identified as an antibiotic for protozoa, and was purified from Streptomyces griseolus (3). It has toxicity for plants, certain protozoa and yeast (4). Anisomycin inhibits protein synthesis in many types of cells by binding to $60 \mathrm{~S}$ ribosomal subunits and blocking formation of peptide bonds (5). In addition, anisomycin induces the apoptosis of several types of in vitro cultured cell lines by activating c-Jun N-terminal protein kinase (JNK) (6-8). During the process of apoptosis, the apoptosis-related proteins Bax, Bak, Bid and caspase, are upregulated, and downregulation of Bcl-2, Bcl-xL, and cytochrome $c$ release from the mitochondria have been confirmed in leukemia cells $(9,10)$. Furthermore, anisomycin-treated cells also show caspase- 8 activation, mitochondrial membrane potential collapse, Bid activation, and cytochrome $c$ release into the cytosol (11). Recently, we found that anisomycin represses the proliferation of 14 different histological types of tumors, and promotes Jurkat $\mathrm{T}$ cell apoptosis in vitro, which involves the inactivation of extracellular regulated kinase $1 / 2$ (ERK1/2), the activation of JNK1/2 and P38 with the upregulation of Bim and the downregulation of Bcl-xL (unpublished data). Therefore, the current study aimed to explore whether anisomycin is able to exert an in vivo antitumor effect on Ehrlich ascites carcinoma.

\section{Materials and methods}

Animals. Male BALB/c mice, 6-8 weeks of age, weighing $20 \pm 2 \mathrm{~g}$, were obtained from the Guangdong Medical Animal Center (Guangzhou, China). Animals were held for a quarantine period of 1 week at a temperature of $25 \pm 2^{\circ} \mathrm{C}$, relative humidity of $55 \pm 2 \%$ and with a 12 -h light/12-h dark cycle. Animal care was in accordance with the institutional guidelines. All animal handling and experimental procedures were approved by the 
Animal Care and Use Committee of Guangdong Medical Animal Center.

Cell culture and treatment. Mouse Ehrlich ascites carcinoma (EAC) cells (ATCC, Beijing Zhongyuan Ltd., China) were cultured in RPMI-1640 medium containing $10 \%$ heat-inactivated fetal bovine serum (FBS) (Gibco-BRL, USA) at $37^{\circ} \mathrm{C}$ in humidified air with $5 \% \mathrm{CO}_{2}$. The cells were incubated for different times with anisomycin (Sigma-Aldrich, St. Louis, MO, USA) at 1, 5, 10, 20, 40, 80 and $160 \mathrm{ng} / \mathrm{ml}$ and then subjected to analysis.

Cell viability. For the assay, EAC cells were plated in 96-well plates at a density of $1 \times 10^{4}$ cells/well/200 $\mu \mathrm{l}$ of medium. The cells were treated with the different concentrations of anisomycin for $48 \mathrm{~h}$. Adriamycin (500 ng/ml) (Zhejiang Hisun Pharmaceutical Co. Ltd., Taizhou, China) was used as a positive control. At the end of a 48 -h incubation, $0.5 \mathrm{mg} / \mathrm{ml}$ of methyl thiazolyl tetrazolium (MTT) (Gibco-BRL) was added to each well. Four hours later, the formazan product of MTT reduction was dissolved in DMSO, and absorbance was measured at $570 \mathrm{~nm}$ using a Model 680 microplate reader (Bio-Rad).

Atomic force microscopy. Auto-probe $\mathrm{CP}$ atomic force microscopy (AFM) (ThermoMicroscopes, Sunnyvale, CA, USA) was used in contact mode to perform the topographic images. The curvature radius of the silicon tip was $<10 \mathrm{~nm}$. As for the tips used in the contact mode, the length, width and thickness of the cantilever were 115,30 and $3.5 \mathrm{~mm}$, respectively. The oscillation frequency was $255 \mathrm{kHz}$, and the force constant was $0.01 \mathrm{~N} / \mathrm{m}$.

DNA ladder. EAC cells were cultured as described above using the different treatments. After the treatments, $1 \times 10^{6}$ cells were lysed and DNA was extracted and purified with an Apoptotic DNA Ladder Kit (Beyotime, Shanghai, China) according to the manufacturer's instructions. An equal amount of purified apoptotic DNA was applied to electrophoresis on a $1.5 \%$ agarose gel. After staining with $1 \mu \mathrm{g} / \mathrm{ml}$ of ethidium bromide, the DNA bands were visualized by UV light and photographed.

Flow cytometry. The EAC cells treated above were stained using an Annexin V/FITC Kit containing propidium iodide (PI) (KeyGEN Biotech, China) according to the manufacturer's instructions and analyzed using a flow cytometer (equipped with a 488-nm argon laser light source; 525-nm band pass filter for FITC-fluorescence; logarithmic scale and 575-nm band pass filter for PI-fluorescence; logarithmic scale) with CellQuest software. Electronic compensation of the instrument was carried out to exclude overlapping of the emission spectra. A total of 10,000 events were acquired, and the cells were properly gated for analysis.

$R T-P C R$. Total RNA in the anisomycin-treated cells was extracted from $3 \times 10^{6}$ cells using an RNeasy Mini kit (Qiagen $\mathrm{GmbH}$, Hilden, Germany) according to the manufacturer's instructions and quantified by measuring the absorbance at $260 \mathrm{~nm}$ using a spectrophotometer. The following primer pairs were used: caspase-3 forward, 5'-GGACTGTGGCATTG
AGACAG-3' and reverse, 5'-CGACCCGTCCTTTGAATT TC-3' (12) (PCR products, $137 \mathrm{bp}$ ); $\beta$-actin forward, 5'-AA CAGTCCGCCTAGAAGCAC-3' and reverse, 5'-CGTTGAC ATCCGTAAAGACC-3' (13) (PCR products, $281 \mathrm{bp}$ ). The One-Step RT-PCR Kit (Qiagen, $\mathrm{GmbH}$ ) was used to analyze the expression of caspase-3 mRNA according to the manufacturer's instructions. The amplified products were size-fractionated by electrophoresis and analyzed using the FluorChem 8000 system (Alpha Innotech, Santa Clara, CA, USA).

Western blotting. EAC cells $\left(2 \times 10^{6}\right)$ were seeded in 12-well plates and treated with anisomycin or adriamycin for $24 \mathrm{~h}$. The cells were washed twice prior to lysis with a RIPA lysis Kit (Beyotime) containing phenylmethanesulfonyl fluoride. The protein concentration in the supernatant was measured with a BCA protein assay kit (Beyotime). An equal amount of the protein was separated by SDS-PAGE and transferred on nitrocellulose membranes (Amersham Biosciences). The membranes were blocked in 5\% nonfat milk in Tris-buffered saline (TBS) for $1 \mathrm{~h}$, and then incubated overnight with anticaspase-3, anti-cleaved-caspase-3, anti-cleaved-caspase-8, anti-cleaved-caspase-9, anti-polyADP-ribose polymerase (PARP) and cleaved-PARP antibodies [(Cell Signaling Technology, Inc. USA) (1:1,000 dilution in TBS with $0.05 \%$ Tween-20 (TBST)], respectively. The membranes were washed three times using TBST and then incubated with horseradish-peroxidase-conjugated IgG antibody (1:2,000) (Cell Signaling Technology) for $1 \mathrm{~h}$. The membranes were developed with ECL Western blotting detection reagent (Thermo Fisher Scientific, Rockford, IL, USA). The band density was tested by the FluorChem 8000 system.

In situ immunofluorescence staining. EAC cells were seeded in a 24 -well plate at a density of $1 \times 10^{4}$ cells/well and treated with $80 \mathrm{ng} / \mathrm{ml}$ anisomycin for $24 \mathrm{~h}$. The cells were washed twice in PBS and fixed with $4 \%$ paraformaldehyde for $30 \mathrm{~min}$. The cells were then washed twice in PBS and blocked with 5\% BSA in PBS for $30 \mathrm{~min}$. Afterwards, the cells were incubated with diluted (in blocking solution) rabbit anti-mouse cleaved-caspase-3 (1:100), cleaved-caspase-8 (1:400) and cleaved-caspase-9 (1:50) antibodies overnight at $4{ }^{\circ} \mathrm{C}$. The cells were then washed three times in PBS and incubated with Alexa Fluor 488-conjugated goat anti-rabbit IgG antibody (1:1,000 diluted in blocking solution) (Cell Signaling Technology, Inc.) at room temperature for $1 \mathrm{~h}$. Furthermore, the cells were incubated with 4',6-diamidino-2-phenylindole (DAPI) for $5 \mathrm{~min}$, and washed with PBS. Finally, the cells were examined under a Leica DMRA2 fluorescence microscope with FW 4000 software (both from Leica, Germany).

In vivo therapy. The animals were subcutaneously inoculated with EAC cells $\left(0.2 \mathrm{ml}\right.$ of $1 \times 10^{7}$ cells/mouse $)$, and divided randomly into three groups $(\mathrm{n}=10)$. The experimental treatment started when the tumor volume reached $\sim 50 \mathrm{~mm}^{3}$. Anisomycin ( $5 \mathrm{mg} / \mathrm{kg}$ ), adriamycin or $100 \mu \mathrm{l}$ of PBS was peritumorally injected into EAC-bearing mice every other day for 7 times. The animals were weighed and inspected daily for survival. The solid tumor sizes were measured every day, and the tumor volumes and tumor growth inhibition rate were calculated by the following formula (14): 

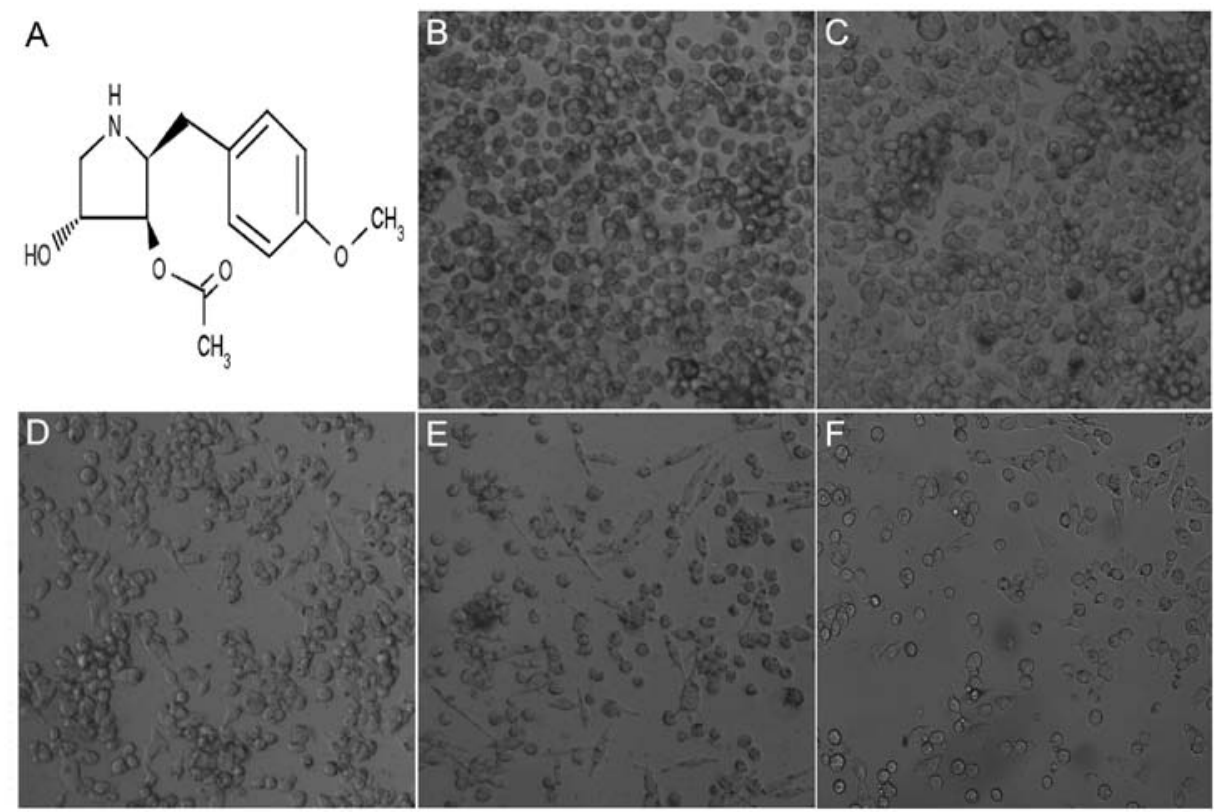

G

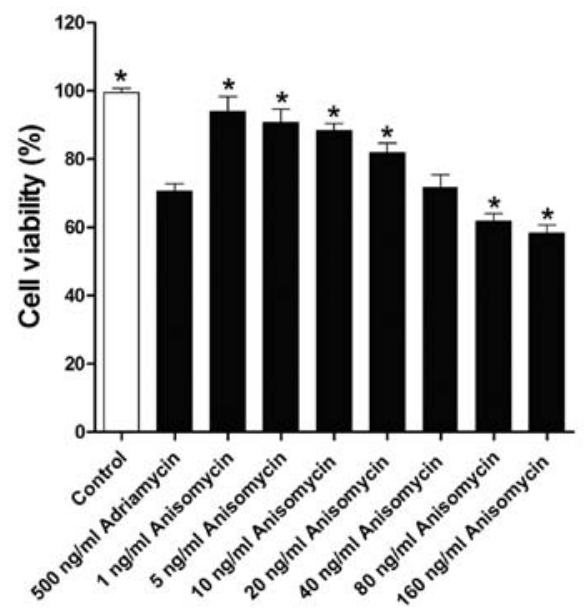

$\mathrm{H}$

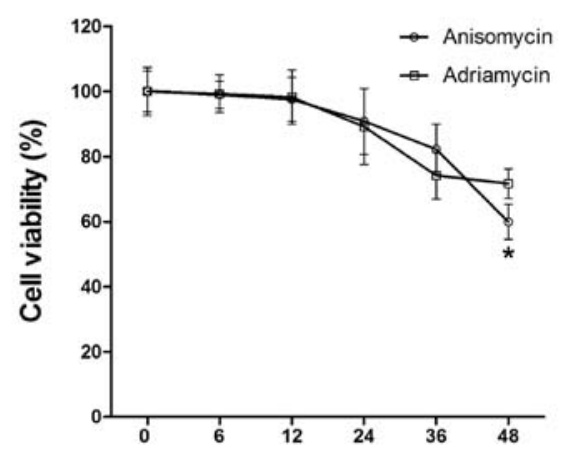

Figure 1. Effect of anisomycin on the in vitro proliferation of EAC cells. (A) Chemical structure of anisomycin. Cultured EAC cells were treated with (B) PBS as a control or (C-E) 10, 40 and $160 \mathrm{ng} / \mathrm{ml}$ of anisomycin, respectively, or (F) $500 \mathrm{ng} / \mathrm{ml}$ of adriamycin for $48 \mathrm{~h}$ and examined under an inverted (x100) microscope. (G) The cell viability following various treatments with anisomycin or $500 \mathrm{ng} / \mathrm{ml}$ adriamycin was determined using the MTT assay. (H) The cell viability following treatment with $80 \mathrm{ng} / \mathrm{ml}$ anisomycin or $500 \mathrm{ng} / \mathrm{ml}$ adriamycin was determined at the different times as indicated. All data values are represented as the means of 3 independent experiments with standard deviation indicated with error bars. " $\mathrm{P}<0.05$ vs. the adriamycin group.

Tumor volume $\left(\mathrm{mm}^{3}\right)=\left(\right.$ length $\mathrm{x}$ width $\left.{ }^{2}\right) / 2$, where the length and width are given in $\mathrm{mm}$.

Tumor inhibition rate $(\%)=[$ (Average tumor volume of the control group - average tumor volume of the test group)/ average tumor volume of the control group] x 100 .

Histopathology. The tumor tissues from the different groups were exised and fixed overnight in $4 \%$ paraformaldehyde solution. Tumor tissues were then embedded in paraffin and processed for construction of $4-\mu \mathrm{m}$ paraffin-embedded sections using a microtome. The paraffin sections were deparaffinized, rehydrated with distilled water, and stained with hematoxylin and eosin (H\&E). The stained tissue sections were then examined and photographed under a light microscope equipped with an OPTEC DV200 digital camera (OPTEC, Ltd., China) to assess infiltration of inflammatory cells in the tumor tissues.
Statistical analysis. Comparison between sets of two groups was performed using the Student's t-test, while sets of more than two groups were compared by ANOVA. Differences between means were considered significant when the two-tailed P-value was $<0.05$.

\section{Results}

Anisomycin inhibits EAC cell proliferation. Anisomycin has a characteristic pyrrolidine structure (Fig. 1A). Compared to the control (Fig. 1B), the number of EAC cells was markedly reduced with increasing doses of anisomycin (Fig. 1C-E) or with adriamycin (Fig. 1F). The cell viability was also decreased with increasing doses of anisomycin. Single administration of $160 \mathrm{ng} / \mathrm{ml}$ of anisomycin reduced the cell viability by $40.34 \%$ at $48 \mathrm{~h}$ (Fig. 1G). The inhibition rate of EAC cell proliferation 


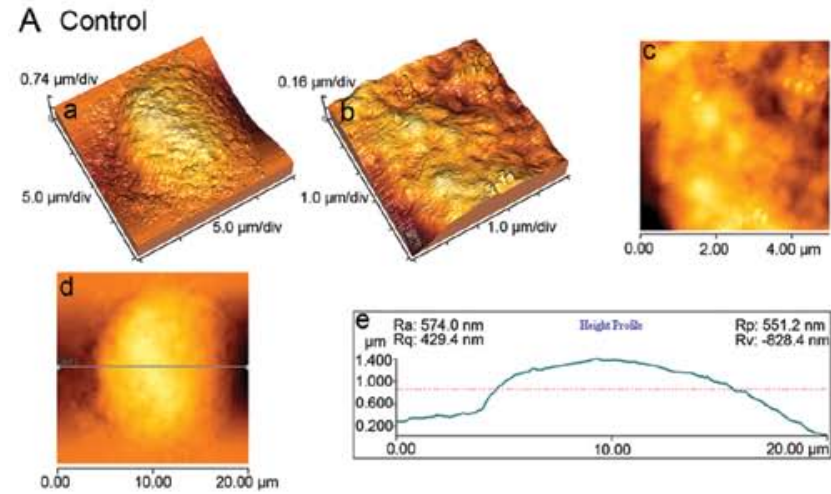

B $10 \mathrm{ng} / \mathrm{ml}$ Anisomycin
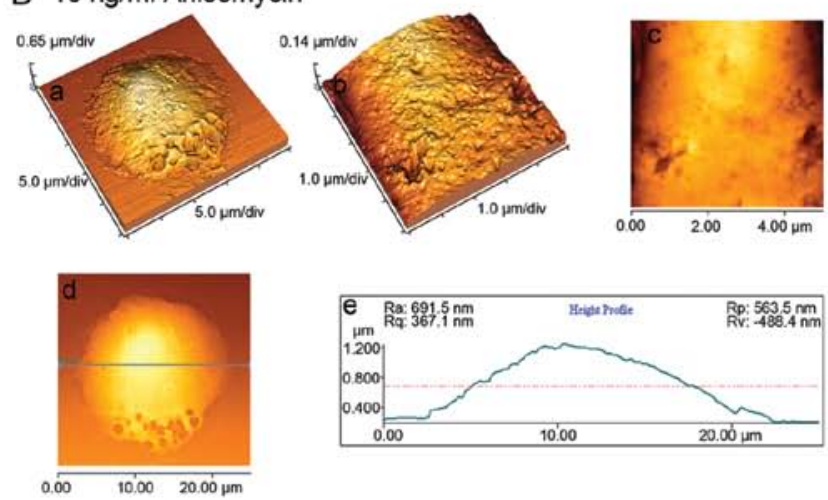

\section{C $40 \mathrm{ng} / \mathrm{ml}$ Anisomycin}
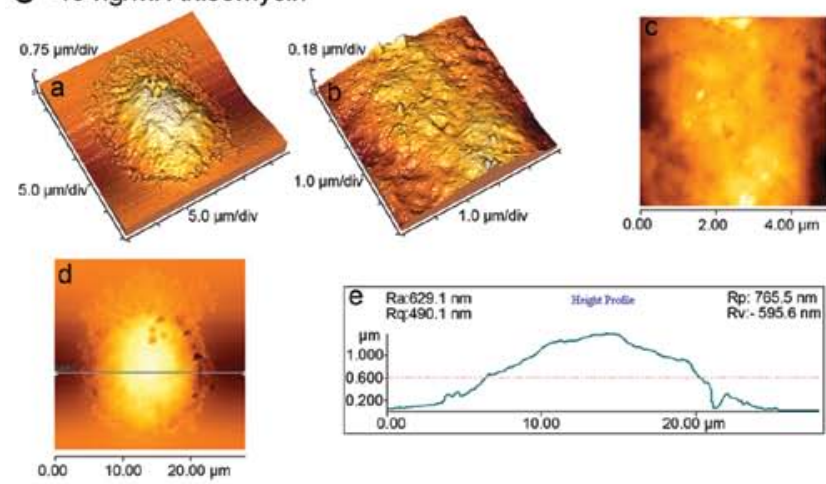

D $160 \mathrm{ng} / \mathrm{ml}$ Anisomycin
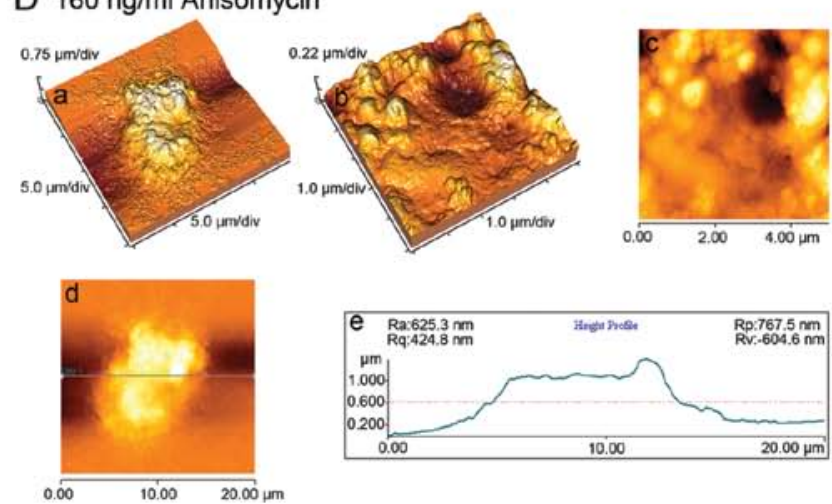

Figure 2. Nanostructure of anisomycin-treated EAC cells observed by AFM. Cultured EAC cells were treated with (A) PBS for $48 \mathrm{~h}$ as a control or (B-D) 10, 40 and $160 \mathrm{ng} / \mathrm{ml}$ of anisomycin for $48 \mathrm{~h}$, respectively. (a) Three dimensional images of the differentially treated whole cells; (b) Locally enlarged images of the three dimensional images of the differentially treated whole cells; (c) Topographic images of b; (d) Topographic images of a; (e) Height profile of d. was increased with prolonged exposure to anisomycin. This growth inhibition rate was lower when compared to the group treated with $500 \mathrm{ng} / \mathrm{ml}$ of adriamycin at $48 \mathrm{~h}$ after treatment $(\mathrm{P}<0.05)$ (Fig. 1H).

Anisomycin causes the alteration in EAC cell nanostructure. Once cells cannot maintain the inherent shape, their function is jeopardized, which causes a range of issues (15). Therefore, AFM was used to observe changes in the nanostructure of anisomycin-treated EAC cells. The three dimension nanostructure of the untreated EAC cells was characterized by a regular shape with a relatively smooth membrane and a higher height profile (Fig. 2A). EAC cells treated with 10 or $40 \mathrm{ng} / \mathrm{ml}$ of anisomycin were similar in nano-characterization to the untreated EAC cells (Fig. 2B and C). In contrast, the cells treated with $160 \mathrm{ng} / \mathrm{ml}$ of anisomycin collapsed obviously, became irregularly shaped and were dramatically deformed with big concavo-convex and lower height profile, suggesting that these cells were undergoing the process of injury and apoptosis (Fig. 2D).

Anisomycin promotes the apoptosis of EAC cells. In comparison with the control, the apoptotic rate of EAC cells was increased with the increasing doses of anisomycin, where the early- and late-stage apoptotic rates of EAC cells reached 22.17 and $10.37 \%$, respectively. Particularly, the early-stage apoptotic rate of EAC cells induced by $160 \mathrm{ng} / \mathrm{ml}$ of anisomycin was higher when compared to the early-stage apoptotic rate induced by $500 \mathrm{ng} / \mathrm{ml}$ of adriamycin, suggesting that the former has a strong role in promoting tumor cell apoptosis (Fig. 3).

Caspase mediates the induction of EAC cell apoptosis by anisomycin. DNA ladder, RT-PCR and western blotting were used to evaluate a relationship between anisomycin-induced apoptosis and expressional patterns of caspase- 3 mRNA, and caspase- 3 and cleaved-caspase- 3 proteins. Consistent with the above data acquired through Annexin V-PI staining, the DNA ladder was gradually formed with increasing doses of anisomycin (Fig. 4A), further supporting the evidence that anisomycin promotes tumor cell apoptosis. Furthermore, the apoptosis of EAC cells was enhanced through the upregulated expression of caspase- 3 mRNA (Fig. 4B), and upregulated expression of cleavedcaspase-8 (Fig. 4C and D), cleaved-caspase-9 (Fig. 4E and F), caspase-3, cleaved caspase-3 (Fig. 4G-J), PARP and cleavedPARP (Fig. 4K and L) proteins following anisomycin treatment in a dose- and exposure time-dependent manner. It was also noted that the levels of caspase- 3 mRNA, and caspase- 3 and cleaved-caspase- 3 proteins induced by 80 and $160 \mathrm{ng} / \mathrm{ml}$ of anisomycin were higher than those induced by $500 \mathrm{ng} / \mathrm{ml}$ of adriamycin. Consistent with the alteration of caspases as described above, in situ immunofluorescence staining also demonstrated the increased expression levels of cleaved-caspase-8 (Fig. 5A-F), cleaved-caspase-9 (Fig. 5G-L) and cleaved-caspase-3 (Fig. 5M-R) in EAC cells treated with $80 \mathrm{ng} / \mathrm{ml}$ of anisomycin; expression was mainly distributed in the nuclei (Fig. 5F, L and R).

Anisomycin extends the survival of EAC cell tumor-bearing mice. As shown in Fig. 6A, the subcutaneous tumor growth 
A
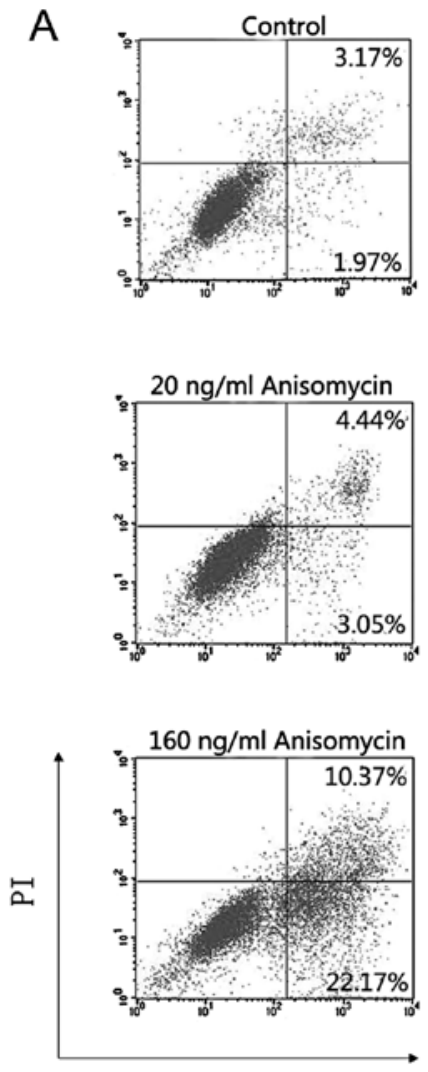

Annexin V-FITC
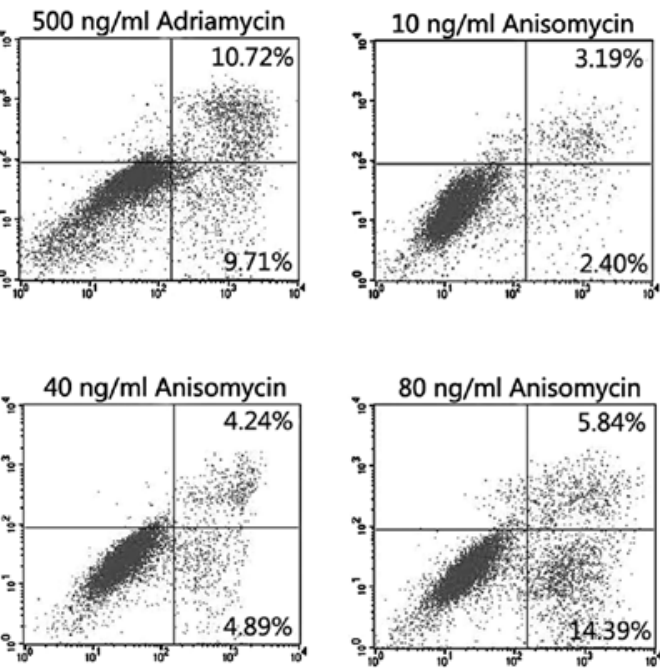

B

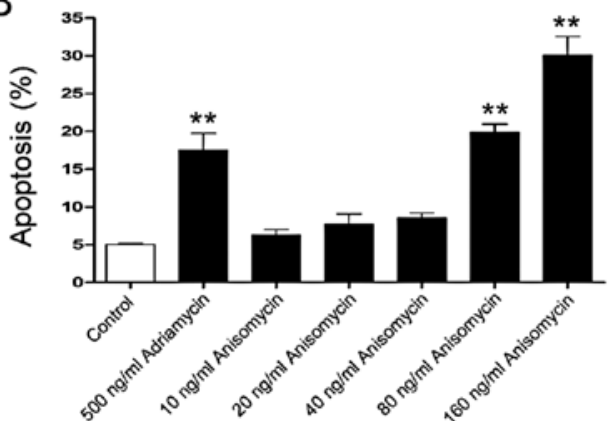

Figure 3. Flow cytometric detection of EAC cell apoptosis. (A) EAC cells were treated with the different concentrations of anisomycin or 500 ng/ml of adriamycin for $48 \mathrm{~h}$, and cell apoptosis was analyzed by flow cytometry. (B) The percentage of the apoptotic cells is shown following statistical analysis. The results are representative of three independent experiments. ${ }^{* *} \mathrm{P}<0.01$ vs. the control group.

of EAC cell tumor-bearing mice was prominently suppressed following treatment with anisomycin or adriamycin. Within 37 days after the inoculation of EAC cells, the therapeutic effect of anisomycin appeared to be superior to that of adriamycin. The growth inhibition of the tumors by anisomycin reached $38.12 \%$ on day 21 after the inoculation, but the inhibition of tumor growth by adriamycin was $20.14 \%$. However, after day 37 the inhibitory rate of tumor growth by anisomycin decreased gradually, but the inhibitory growth rate of the tumors by adriamycin continued to increase, reaching $58.30 \%$ on day 57 (Fig. 6B). As shown in Fig. 6C, the survival rate of the $5 \mathrm{mg} / \mathrm{kg}$ anisomycin-treated mice reached $\sim 60 \%$ on day 85 after inoculation, much higher than that of the control mice or $5 \mathrm{mg} / \mathrm{kg}$ adriamycin-treated mice $(\mathrm{P}<0.05)$. All anisomycin-treated mice died by the end of the 120-day period after inoculation, but all adriamycin-treated mice died before day 90 . Notably, the spleen to body weight ratio in the anisomycin-treated mice was much higher than that in the control $(\mathrm{P}<0.05)$, but this ratio of the adriamycin-treated mice was lower than that in the control although there was no statistical difference, suggesting that anisomycin may have a stimulatory effect on peripheral immunological organs (Fig. 6D). In addition, images of in situ tumor growth offered visible evidence to support the therapeutic effect of anisomycin or adriamycin as described above (Fig. 6E). Compared with the control, H\&E staining showed that there was higher inflammatory cell infiltration in the tumor tissues of anisomycin-treated mice than that in the PBS-treated or adriamycin-treated mice, respectively (Fig. 6F).

\section{Discussion}

Anisomycin induces apoptosis of human prostate carcinoma DU145 cells (16), human lymphoma U937 cells (17), and mouse fibroblast AKR-2B cells in vitro (18). Hori et al (11) found that U937 cells treated in vitro by anisomycin displayed caspase- 8 activation, mitochondrial membrane potential collapse, Bid activation, and cytochrome $c$ release into the cytosol. In addition, the expression of EIF4 family and ribosomal proteins was inhibited (19). We also found that anisomycin suppressed proliferation of 14 different histological types of tumors, and promoted Jurkat $\mathrm{T}$ cell apoptosis in vitro, which involved the inactivation of ERK1/2, the activation of JNK1/2 and P38 with the upregulation of Bim and the downregulation of Bcl-xL (unpublished data). Therefore, we hypothesized that based on the potent inhibition of intracellular protein synthesis and strong induction of cell apoptosis by anisomycin, it should have a therapeutic effect on in vivo tumors. Thus, tumor-bearing mice were utilized to test this hypothesis.

Liu et al (20) reported that anisomycin induced expression of FoxP3 in both normal and malignant mammary epithelial cells, which was mediated by ATF2 and c-Jun. Simultaneously, they preliminarily treated TSA (a mouse mammary tumor cell line)-bearing mice intraperitoneally with anisomycin at a dose 
A

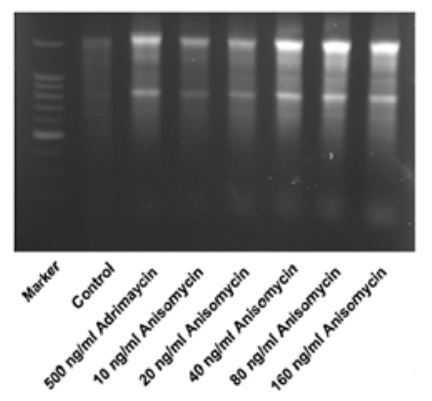

E

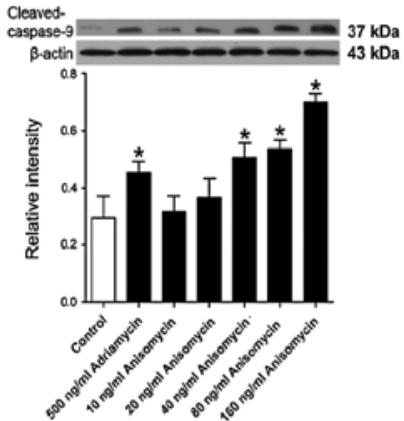

I
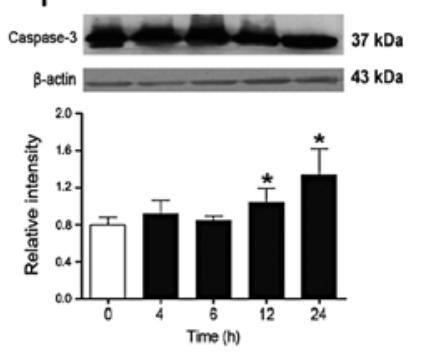

B
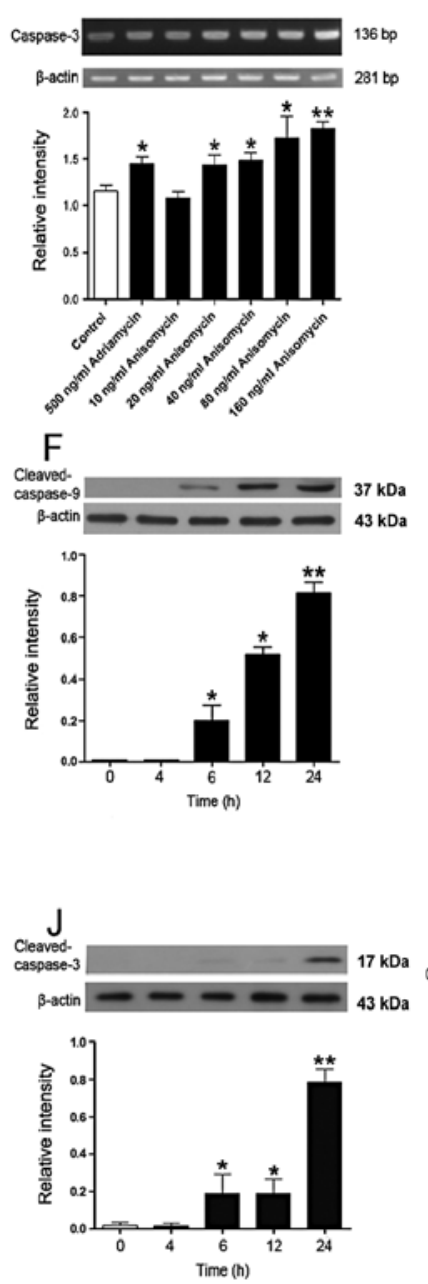

C

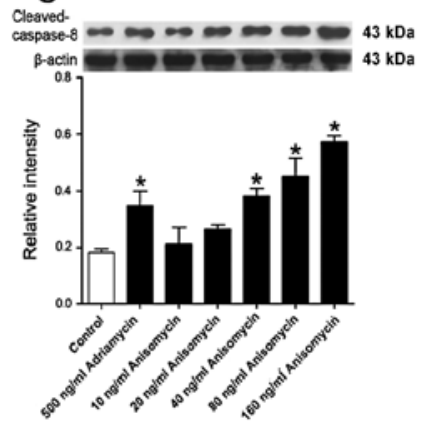

G
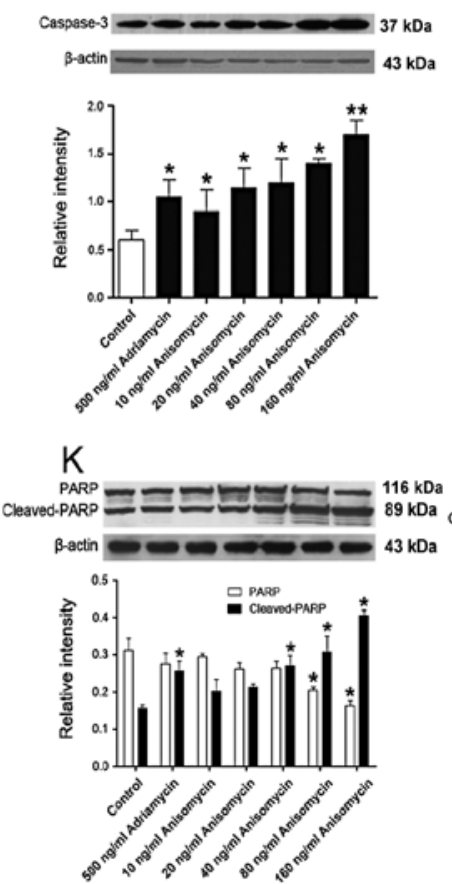
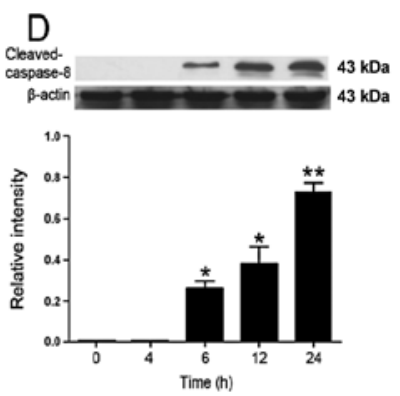

H

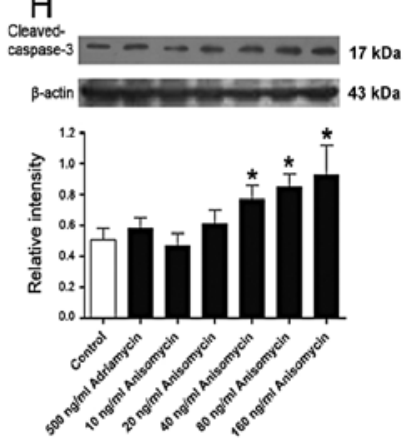

$\mathrm{L}$

DPARP $=\begin{gathered}116 \mathrm{kDa} \\ 89 \mathrm{kDa}\end{gathered}$
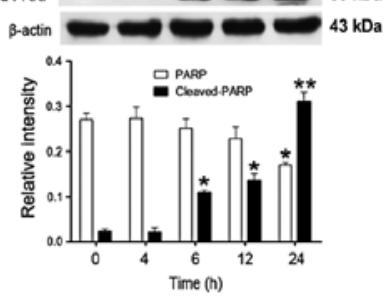

Figure 4. Relationship between caspases and EAC cell apoptosis induced by anisomycin. In vitro cultured EAC cells were treated with anisomycin for 24 h. (A) DNA ladder formation was tested by DNA ladder assay. (B) Expression of caspase-3 mRNA was evaluated by RT-PCR. (C-L) Levels of caspase proteins were determined by western blotting. (C) For cleaved-caspase- 8 protein, the cells were treated with different concentrations of anisomycin for $24 \mathrm{~h}$, or (D) with $80 \mathrm{ng} / \mathrm{ml}$ of anisomycin for the indicated times. (E) For cleaved-caspase- 9 protein, the cells were treated with the different concentrations of anisomycin for $24 \mathrm{~h}$ or (F) with $80 \mathrm{ng} / \mathrm{ml}$ of anisomycin at the indicated times. ( $\mathrm{G}$ and $\mathrm{H}$ ) For caspase-3 or cleaved-caspase-3 protein, the cells were treated with the different concentrations of anisomycin for $24 \mathrm{~h}$ or ( $\mathrm{I}$ and $\mathrm{J}$ ) with $80 \mathrm{ng} / \mathrm{ml}$ of anisomycin at the indicated times. (K) For PARP or cleaved-PARP protein, the cells were treated with the different concentrations of anisomycin for $24 \mathrm{~h}$ or $(\mathrm{L})$ with $80 \mathrm{ng} / \mathrm{ml}$ of anisomycin at the indicated time. ${ }^{*} \mathrm{P}<0.05$ and ${ }^{* *} \mathrm{P}<0.01 \mathrm{vs}$. the control.

of $0.5 \mathrm{mg} / \mathrm{mouse}$. Their data revealed that a low dose of anisomycin was markedly effective in treating TSA-bearing mice. To date, this was an exclusive report involving the administration of anisomycin to treat tumors. Yet, only the tumor volume for evaluating the therapeutic effect was investigated during a two-week period. Our results indicated that anisomycin significantly extended the survival of EAC tumor-bearing mice, superior to an equal dose of adriamycin. This was consistent with the inhibition of proliferation of EAC cells by the in vitro treatment of anisomycin. This was further supported by anisomycin-induced EAC cell apoptosis with the nanostructure alteration of cells as observed under AFM and with the enhancement of infiltrating lymphocytes in the tumor tissue. However, it is noted that at the early stage of tumor growth the inhibitory effect of anisomycin on the tumors was superior to that of adriamycin, but at the late stage the effect of the former was inferior to adriamycin. Thus, we aimed to ascertain why the survival time of EAC tumor- bearing mice treated by adriamycin was still much shorter than the survival time of mice treated with anisomycin. We proposed that the shorter survival time of the adriamycin-treated group may be related to tumor cell invasion and distant metastasis. Mawji et al (21) utilized image-based analysis to quantify the metastasis of dsRed-PPC-1 cells to liver, lung and bone. They found that mice inoculated intravenously with in vitro anisomycin-treated cells had a markedly decreased tumor count and area within the liver, lung and bone. Anisomycin decreased levels of the caspase- 8 inhibitor FLIP in malignant epithelial cells in blood, subsequently activating the death receptor pathway of caspase activation to inhibit the survival of circulating tumor cells and thereby preventing distal tumor metastases in prostate cancer-bearing mice. This may explain why the survival rate of the anisomycin-treated group was much higher than that of the adriamycin-treated group although the tumor inhibition rate of the latter was higher than that of 

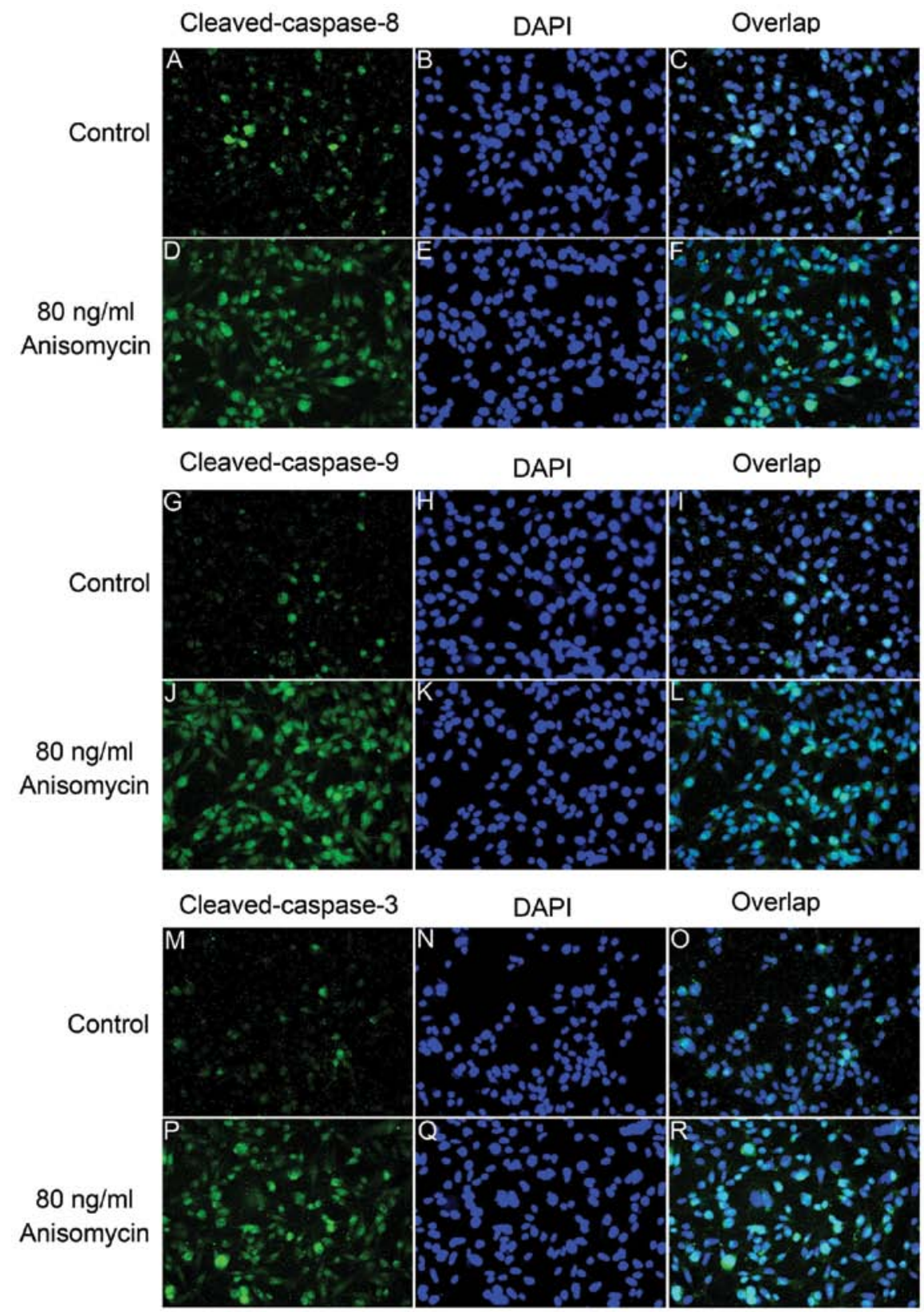

Figure 5. In situ immunofluorescence staining of cleaved caspases in EAC cells treated with $80 \mathrm{ng} / \mathrm{ml}$ anisomycin. In vitro cultured EAC cells were treated with $80 \mathrm{ng} / \mathrm{ml}$ of anisomycin for $24 \mathrm{~h}$. The cells were then fixed, permeabilized, and stained with monoclonal antibodies specific for cleaved-caspase-3, -8 and $-9(\mathrm{x} 400$, green). The results are representative of at least 3 independent experiments.

the former at the late stage. In other words, distant metastasis may have led to mouse death in the adriamycin-treated group or anisomycin may have impeded metastasis via reduction in FLIP, which deserves further investigation. In addition, anisomycin was found to induce rapid apoptosis in human lymphoid cells (22) in contrast with the delayed apoptosis induced by many other protein synthesis inhibitors that do not activate JNK and p38 (17,23), suggesting an important role of these kinases in anisomycin-induced apoptosis in tumor cells (23). This may be a reason why the therapeutic effect of anisomycin occurs earlier than that of adriamycin. Certainly, the therapeutic regimen needs to be optimized to gain the best effect.

Apoptosis involves a process characterized by DNA fragmentation, a decrease in cell volume, chromatin condensation, cell surface blebbing, and formation of apoptotic bodies (24).
It has been shown that anisomycin induces cell apoptosis through activating p38 (25-27) and JNK signaling pathways $(16,25)$. Croons et al $(28)$ showed that anisomycin induced apoptosis of macrophages in vitro and selectively decreased the macrophage content through apoptosis in vivo, indicating that p38 MAPK, but not ERK1/2 or JNK, plays a major role in anisomycin-induced macrophage death. Dissimilarly, our previous study supports that JNK, but not $\mathrm{p} 38$, plays a major role in anisomycin-induced Jurkat $\mathrm{T}$ cell apoptosis. Hoppe et al (18) found that anisomycin led to a strong activation of p38 kinase and jun kinase, but it was not sufficient for the activation of caspase-3. They further disclosed the activation of caspase-12 in AKR-2B cells following the addition of anisomycin. It is well known that caspase- 3 is a dominant executioner among the caspase family members. Our results 

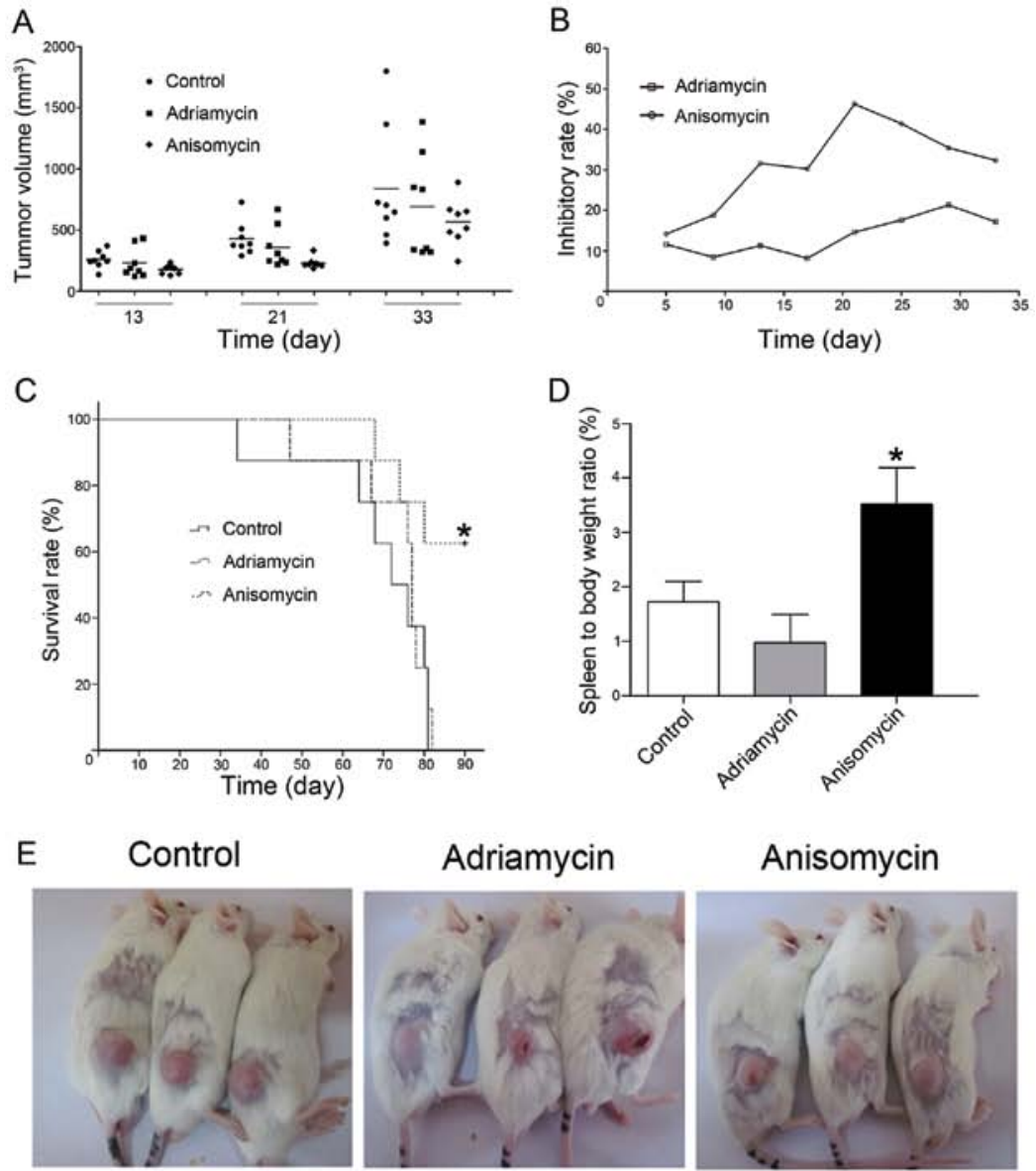

Anisomycin
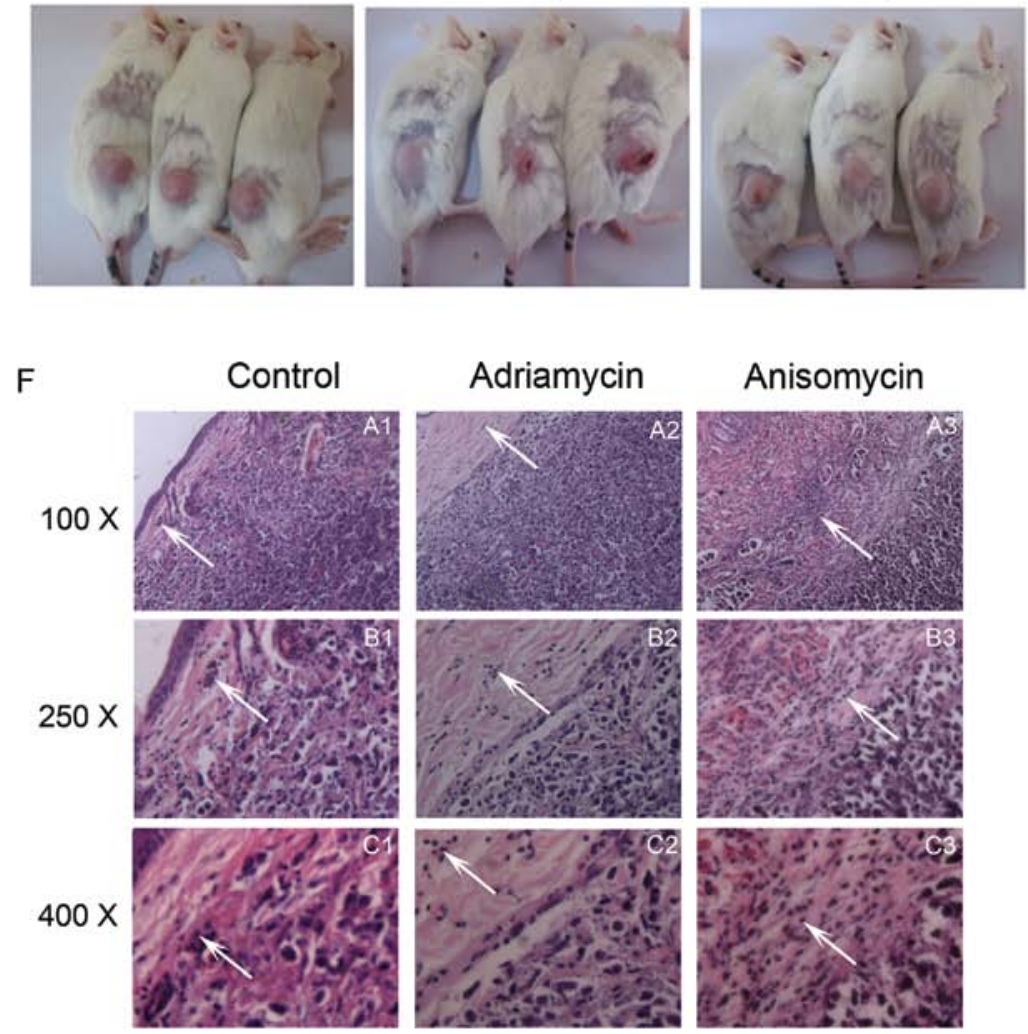

\section{Anisomycin}
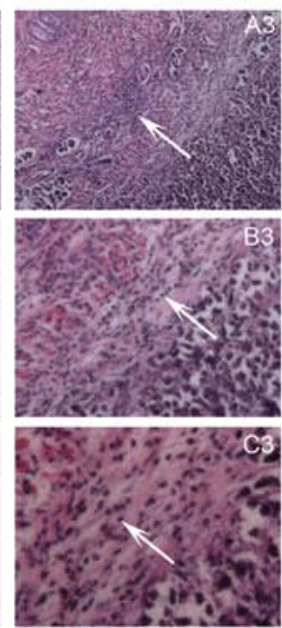

Figure 6. In vivo therapeutic effect of anisomycin on EAC tumor-bearing mice. (A) Distribution of the tumor volume for each EAC tumor-bearing mouse is indicated on days 13, 21 and 33 after treatment with anisomycin or adriamycin. (B) Inhibitory rate of EAC tumor growth by $5 \mathrm{mg} / \mathrm{kg}$ of anisomycin compared with adriamycin was determined. (C) Survival rate of EAC tumor-bearing mice treated with anisomycin is shown for 90 days after the inoculation of EAC cells. (D) Spleen to body weight ratio of the mice. (E) Images of the EAC tumor-bearing mice treated with anisomycin or adriamycin captured 35 days after cell inoculation. (F) Paraffin-embedded tumor tissue sections were stained with H\&E. Inflammatory cell infiltration in the tumor tissues was observed (white arrows). ${ }^{*} \mathrm{P}<0.05$ when compared to control and adriamycin-treated mice.

showed that, consistent with the extent of EAC cell apoptosis, the level of caspase-3 mRNA, and the levels of cleavedcaspase-8, cleaved-caspase-9, caspase-3, cleaved-caspase-3 and PARP proteins in anisomycin-treated EAC cells were increased in a dose- and time-dependent manner, followed by PARP cleavage. Moreover, these results were further supported by the in situ increase in cleaved-caspase- 8 , cleavedcaspase- 9 and cleaved caspase- 3 proteins. Therefore, EAC cell apoptosis induced by anisomycin is possibly realized through activation of the caspase cascade. Another research group demonstrated that malignant mesothelioma cells are rapidly sensitized to tumor necrosis factor-related apoptosis inducing 
ligand (TRAIL)-induced apoptosis at subtoxic concentrations of anisomycin (10- to 100-fold below concentrations required to inhibit protein translation) via posttranslational potentiation of Bim that is relevant to the activation of JNK signaling (29). Similarly, our data revealed that anisomycin induced Jurkat $\mathrm{T}$ cell apoptosis through the upregulation of Bim and the downregulation of Bcl-XL mediated by the activation of the JNK1/2 signaling pathway (unpublished data). Macrophage inhibitory cytokine-1 (MIC-1) is also a critical inducer of apoptosis-related gene products. Expression of the $M I C-1$ gene stimulated by anisomycin treatment is enhanced by the p38-ATF-3 signaling pathway, subsequently leading to apoptosis in colon cancer cells (30). Therefore, the detailed mechanisms of anisomycin-induced tumor cell apoptosis require further elucidation.

Notably, our data showed that the mouse spleen in the anisomycin-treated group was much larger than the spleens in the adriamycin- or PBS-treated groups. In contrast, the mouse spleen in the adriamycin-treated group was smaller than that in the PBS-treated group although no statistical difference was achieved. This role for anisomycin was also confirmed in our previous study using a consecutive four-week intravenous administration of anisomycin, resulting in a dose-dependent relationship. Mouse thymus development was prominently suppressed by anisomycin treatment (31). According to the increase in spleen enlargement combined with the increase in infiltrating lymphocytes in the anisomycin-treated tumor tissue, the antitumor effect of anisomycin may be relevant to its stimulation of peripheral immune organs along with its ability to induce tumor cell apoptosis. The molecular events and their significance involving the increased mouse spleen weight by anisomycin remain to be elucidated.

In conclusion, the potential of anisomycin to be applied to treat in vivo tumors was investigated. Our results indicate that anisomycin efficaciously inhibited EAC tumor growth and extended the survival of EAC tumor-bearing mice. The effects of anisomycin were superior to those of adriamycin, which was possibly mediated partly through caspase- 3 signaling which promoted EAC cell apoptosis. The precise mechanisms remain to be elucidated.

\section{Acknowledgements}

This study was supported by the National Natural Science Foundation of China (nos. 81172824, 30971465 and 30471635) and the '211' project grant.

\section{References}

1. Zhang L and Demain AL (eds): Natural Products: Drug Discovery and Therapeutic Medicine, Humana Press, Totowa, NJ, 2005.

2. El-Refaei MF and El-Naa MM: Inhibitory effect of caffeic acid phenethyl ester on mice bearing tumors involving angiostatic and apoptotic activities. Chem Biol Interact 186: 152-156, 2010.

3. Sobin BA and Tanner FW: Anisomycin, a new anti-protozoan antibiotic. J Am Chem Soc 76: 4053, 1954.

4. Grollman AP: Inhibitors of protein biosynthesis. II. Mode of action of anisomycin. J Biol Chem 242: 3226-3233, 1967.

5. Barbacid $M$ and Vazquez D: Ribosome changes during translation. J Mol Biol 93 : 449-463, 1975.

6. Xia Z, Dickens M, Raingeaud J, Davis RJ and Greenberg ME: Opposing effects of ERK and JNK-p38 MAP kinases on apoptosis. Science 270: 1326-1331, 1995.
7. Zanke BW, Boudreau K, Rubie E, Winnett E, Tibbles LA, Zon L, Kyriakis J, Liu FF and Woodgett JR: The stress-activated protein kinase pathway mediates cell death following injury induced by cis-platinum, UV irradiation or heat. Curr Biol 6: 606-613, 1996.

8. Park J, Kim I, Oh YJ, Lee K, Han PL and Choi EJ: Activation of c-Jun N-terminal kinase antagonizes an anti-apoptotic action of Bcl-2. J Biol Chem 272: 16725-16728, 1997.

9. Sun HY, Wang NP, Halkos M, Kerendi F, Kin H and Guyton RA, Vinten-Johansen J and Zhao ZQ: Postconditioning attenuates cardiomyocyte apoptosis via inhibition of JNK and p38 mitogenactivated protein kinase signaling pathways. Apoptosis 11: 1583-1593, 2006.

10. Ganju N and Eastman A: Bcl-X(L) and calyculin A prevent translocation of Bax to mitochondria during apoptosis. Biochem Biophys Res Commun 291: 1258-1264, 2002.

11. Hori T, Kondo T, Tabuchi Y, Takasaki I, Zhao QL, Kanamori M, Yasuda T and Kimura T: Molecular mechanism of apoptosis and gene expressions in human lymphoma U937 cells treated with anisomycin. Chem Biol Interact 172: 125-140, 2008.

12. Rajesh M, Mukhopadhyay P, Bátkai S, Mukhopadhyay B, Patel V, Haskó G, Szabó C, Mabley JG, Liaudet L and Pacher P: Xanthine oxidase inhibitor allopurinol attenuates the development of diabetic cardiomyopathy. J Cell Mol Med 13: 2330-2341, 2009.

13. Choi JW, Pampeno C, Vukmanovic S and Meruelo D: Characterization of the transcriptional expression of Notch-1 signaling pathway members, Deltex and HES-1, in developing mouse thymocytes. Dev Comp Immunol 26: 575-588, 2002.

14. Malik F, Kumar A, Bhushan S, Mondhe DM, Pal HC, Sharma R, Khajuria A, Singh S, Singh G, Saxena AK, Suri KA, Qazi GN and Singh J: Immune modulation and apoptosis induction: Two sides of antitumoural activity of a standardised herbal formulation of Withania somnifera. Eur J Cancer 45: 1494-1509, 2009.

15. Bieling P, Laan L, Schek H, Munteanu EL, Sandblad L, Dogterom M, Brunner D and Surrey T: Reconstitution of a microtubule plus-end tracking system in vitro. Nature 450: 1100$1105,2007$.

16. Curtin JF and Cotter TG: Anisomycin activates JNK and sensitises DU 145 prostate carcinoma cells to Fas mediated apoptosis. Br J Cancer 87: 1188-1194, 2002.

17. Kochi SK and Collier RJ: DNA fragmentation and cytolysis in U937 cells treated with diphtheria toxin or other inhibitors of protein synthesis. Exp Cell Res 208: 296-302, 1993.

18. Hoppe J, Kilic M, Hoppe V, Sachinidis A and Kagerhuber U: Formation of caspase-3 complexes and fragmentation of caspase-12 during anisomycin-induced apoptosis in AKR-2B cells without aggregation of Apaf-1. Eur J Cell Biol 81: 567-576, 2002.

19. Hernández G and Vazquez-Pianzola P: Functional diversity of the eukaryotic translation initiation factors belonging to eIF4 families. Mech Dev 122: 865-876, 2005.

20. Liu Y, Wang Y, Li W, Zheng P and Liu Y: Activating transcription factor 2 and c-Jun-mediated induction of FoxP3 for experimental therapy of mammary tumor in the mouse. Cancer Res 69: 5954-5960, 2009.

21. Mawji IA, Simpson CD, Gronda M, Williams MA, Hurren R, Henderson CJ, Datti A, Wrana JL and Schimmer AD: A chemical screen identifies anisomycin as an anoikis sensitizer that functions by decreasing FLIP protein synthesis. Cancer Res 67: 8307-8315, 2007.

22. Polverino AJ and Patterson SD: Selective activation of caspases during apoptotic induction in HL-60 cells. Effects of a tetrapeptide inhibitor. J Biol Chem 272: 7013-7021, 1997.

23. Sugita M, Morita T and Yonesaki T: Puromycin induces apoptosis of developing chick sympathetic neurons in a similar manner to NGF-deprivation. Zoolog Sci 12: 419-425, 1995.

24. Achenbach TV, Slater EP, Brummerhop H, Bach T and Müller R: Inhibition of cyclin-dependent kinase activity and induction of apoptosis by preussin in human tumor cells. Antimicrob Agents Chemother 44: 2794-2801, 2000.

25. Bébien M, Salinas S, Becamel C, Richard V, Linares L and Hipskind RA: Immediate-early gene induction by the stresses anisomycin and arsenite in human osteosarcoma cells involves MAPK cascade signaling to Elk-1, CREB and SRF. Oncogene 22: 1836-1847, 2003.

26. Rosser EM, Morton S, Ashton KS and Hulme AN: Synthetic anisomycin analogues activating the JNK/SAPK1 and p38/SAPK2 pathways. Org Biomol Chem 2: 142-149, 2004. 
27. Xiong W, Kojic LZ, Zhang L, Prasad SS, Douglas R, Wang Y and Cynader MS: Anisomycin activates p38 MAP kinase to induce LTD in mouse primary visual cortex. Brain Res 1085: 68-76, 2006.

28. Croons V, Martinet W, Herman AG, Timmermans JP and De Meyer GR: The protein synthesis inhibitor anisomycin induces macrophage apoptosis in rabbit atherosclerotic plaques through p38 mitogen-activated protein kinase. J Pharmacol Exp Ther 329: 856-864, 2009.

29. Abayasiriwardana KS, Barbone D, Kim KU, Vivo C, Lee KK Dansen TB, Hunt AE, Evan GI and Broaddus VC: Malignant mesothelioma cells are rapidly sensitized to TRAIL-induced apoptosis by low-dose anisomycin via Bim. Mol Cancer Ther 6 : 2766-2776, 2007.
30. Yang H, Choi HJ, Park SH, Kim JS and Moon Y: Macrophage inhibitory cytokine-1 (MIC-1) and subsequent urokinase-type plasminogen activator mediate cell death responses by ribotoxic anisomycin in HCT-116 colon cancer cells. Biochem Pharmacol 78: 1205-1213, 2009.

31. Tang Z, Xing F, Chen D, Yu Y, Yu C, Di J and Liu J: In vivo toxicological evaluation of anisomycin. Toxicol Lett 208: 1-11, 2012. 